\title{
Reconfigurable Filter Design Using Novel Resonators
}

\author{
Ayse Nihan Basmaci ${ }^{1}$, Ceyhun Karpuz ${ }^{2}$, Fatih Tulumbaci $^{3}$ \\ ${ }^{1,3}$ Tekirdag Namik Kemal University \\ Suleymanpasa, Tekirdag, Turkey \\ anbasmaci@nku.edu.tr; ckarpuz@pau.edu.tr \\ ${ }^{2}$ Pamukkale University \\ Merkez, Denizli, Turkey \\ ftulumbaci@nku.edu.tr
}

\section{Extended Abstract}

The structure proposed in this study is basically a meander-shaped resonator structure. By changing certain parameters determined on this structure, the filtering characteristics can be adjusted. For instance, the bandpass filtering characteristic can be adjusted as elliptical or linear phase by means of adjustments made in the value of the capacitor added to the structure. The effects of coupling and perturbation level on the frequency response in the proposed structure are also investigated. If the coupling level is not sufficient, the filter does not respond. In the proposed filter structure, the filtering characteristic can be adjusted by changing the capacity value. The structure can be reconfigurable with the adjustments made on the main transmission line of the structure, allowing the transition of the structure from the band-pass filtering characteristic to the band-stop filtering characteristic. Moreover, by increasing the capacity value the frequency response can be also switched from single mode to dual mode. The simulations in this study were performed with the help of SONNET SOFTWARE, a full-wave EM (Electro-Magnetic) simulator package program. Theoretical analysis of the proposed filter performed by obtaining the equivalent circuit model of the proposed structure. Scattering and ABCD matrix of the proposed structure are also extracted to clarify the filter topology. A reconfigurable microwave filter is designed, simulated and analysed theoretically. It should be noted that, simulation results and theoretically obtained results are in a very good agreement with the predicted results.

\section{References}

[1] Rauscher C., "Reconfigurable bandpass filter with a three-to-one Switchable Passband Width", IEE Transactions on Microwave Theory and Techniques, vol. 52, no. 2, part 1, pp. 573-577, 2003.

[2] W. M. Fathelbab and M. B. Steer, "A reconfigurable bandpass filter for RF/microwave multifunctional systems", IEEE Trans. Microw. Theory Tech., vol.53, no.3, pp.1111, 1116, 2005.

[3] Y. Zhao, T. Liu, X. Tiefeng, Q. Nie, Y. Xia, R. Wang, G. Jiang and Y. Ye, "Varactor-tuned dual-band filter with constant absolute bandwidth", IEEE MTT-S Int. Microw. Symp. Digest (MTT), vol., no., pp.1,3, 17-22, 2012.

[4] X. Huang, L. Zhu, Q. Feng, Q. Xiang and D. Jia, "Tunable bandpass filter with independently controllable dual passbands", IEEE Transactions on Microwave Theory and Techniques, vol. 61, no. 9, pp. 3200-3208, 2013.

[5] M. F. Lei and H. Wang, "An analysis of miniaturized dual-mode bandpass filter structure using shunt-capacitance perturbation," in Microwave Theory and Techniques, IEEE Transactions, vol. 53, no. 3, pp. 861-867, 2005.

[6] M. F. Karim, A. Q. Lui, A. Alphones, and A. B. Yu, "A novel reconfigurable filter using periodic structures", in Proceedings of IEE MTT-S International Microwave Symposium, pp. 943-946, 2006.

[7] Lugo C. Jr. and Papapolymerou J., "Dual mode reconfigurable filter with asymmetrical transmission zero and center frequency control", IEE Microwave and Wireless Component Letters, vol. 16, no. 9, pp. 499-501, (2006).

[8] A. Gorur, "Description of coupling between degenerate modes of a dual-mode microstrip loop resonator using a novel perturbation arrangement and its dual-mode bandpass filter applications", IEEE Transactions Microwave Theory and Techniques, pp. 671-677, 2004. 